\title{
Rückblick auf den FMH-Tarifdelegierten-Tag
}

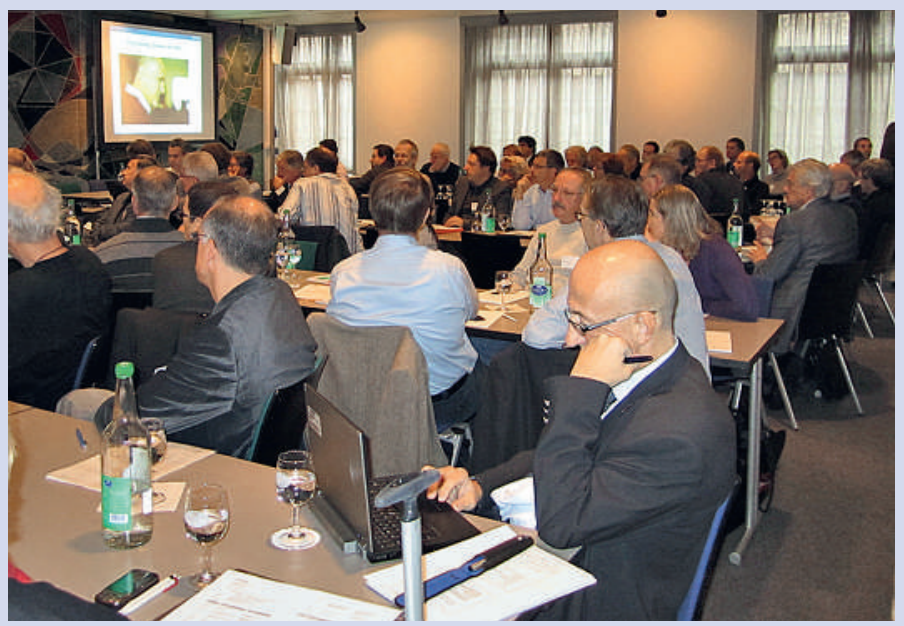

Der Tarifdelegierten-Tag am 20. Oktober 2011 im Hotel Bern war sehr gut besucht, wir konnten rund 80 Gäste begrüssen.

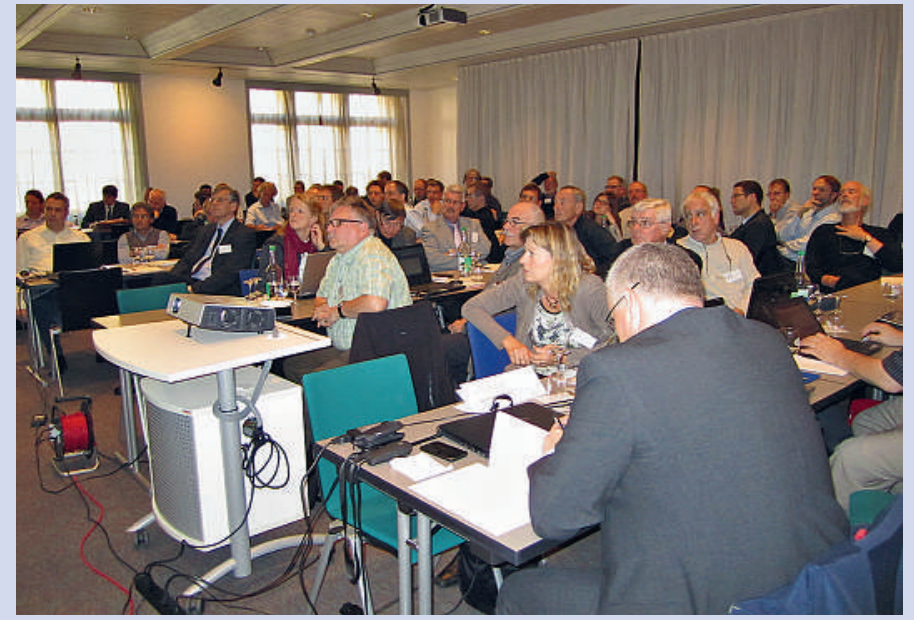

Das spezifische Plenumsreferat zum Stand unseres Projektes TARVISION, der Tarifrevision TARMED, zeigte aus verschiedenen Blickwinkeln und vorgetragen von unseren Tarifexperten auf, wie weit das vor einem Jahr gestartete Projekt schon ist.

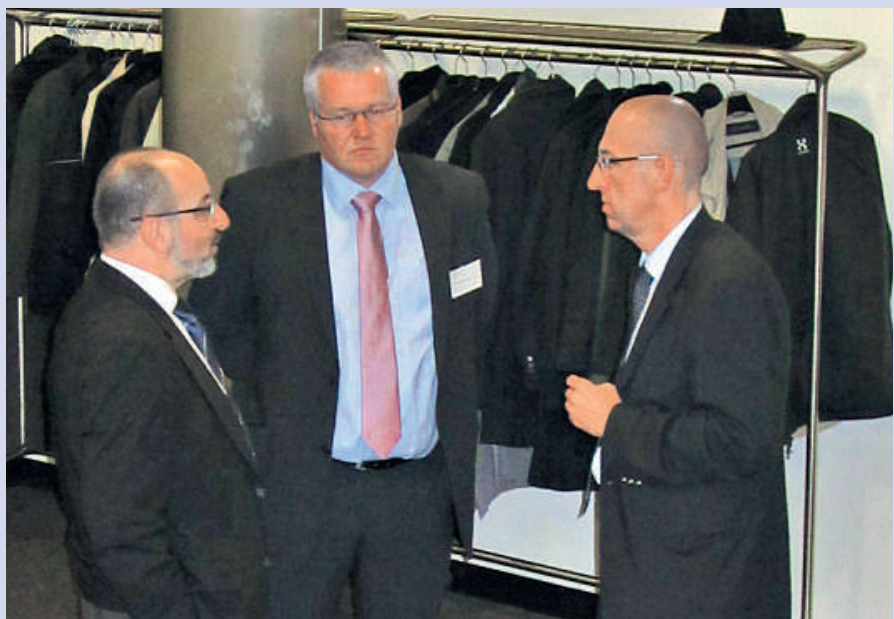

Die Impulsreferate von Dr. iur Andreas Faller, Vizedirektor BAG, ...

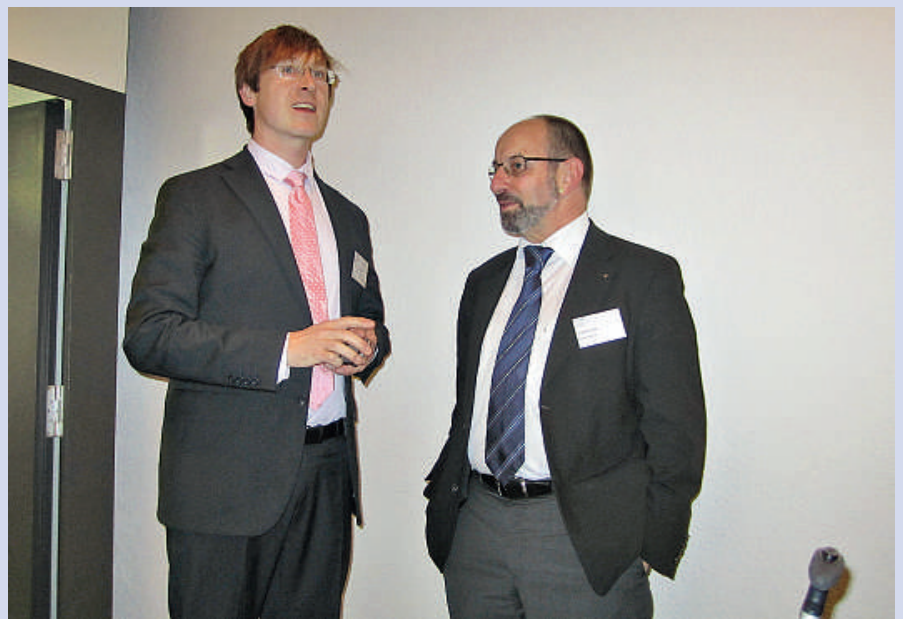

... und Dr. iur. Stefan Meierhans, Preisüberwacher, gaben Anlass zu angeregten Diskussionen unter den Tarifdelegierten und mit den Referenten. 


\section{Referate und Workshops}

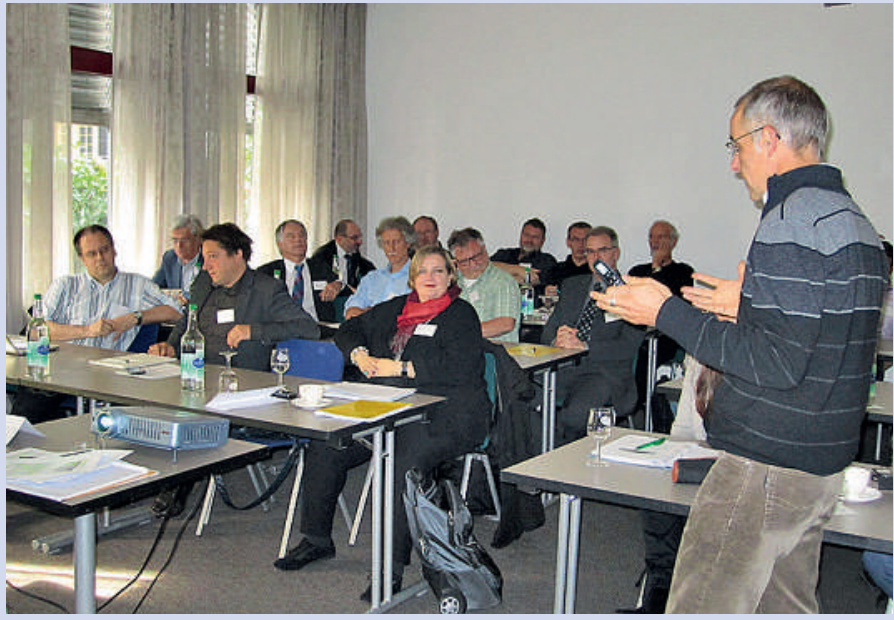

Die Delegierten, die ein Praxislabor betreiben, waren gespannt auf die Ergebnisse, welche die Autoren der Studie des Winterthurer Instituts für Gesundheitsökonomie über die Kosten eines Praxislabors präsentierten. Unsere bereits bei Einführung der neuen Analyseliste bemängelten, nicht sachgerechten und nicht kostendeckenden Berechnungen wurden bestätigt.

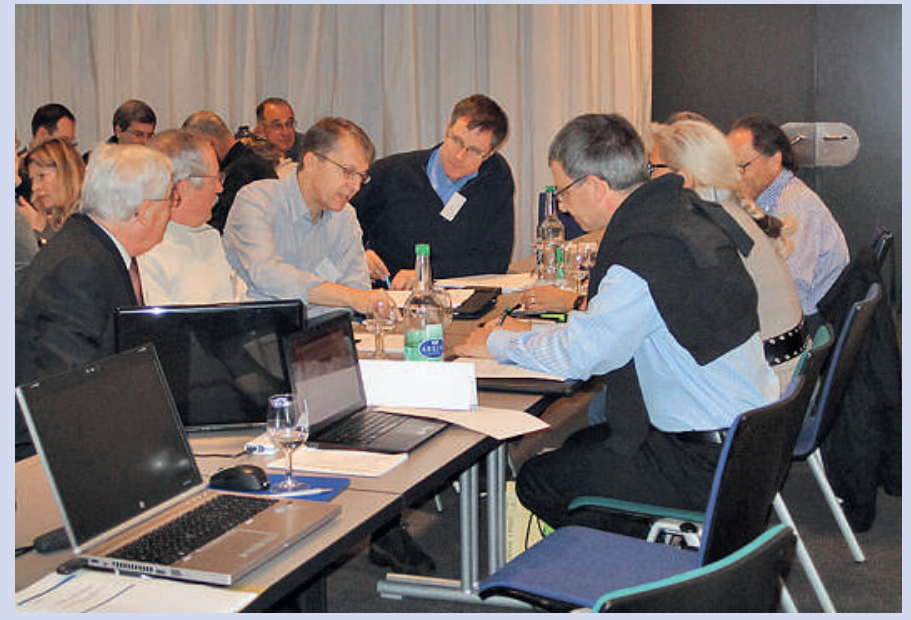

Gleichzeitig zum Workshop vom Praxislabor konnte die andere Hälfte der Tarifdelegierten heikle und brisante Verrechnungsfragen aus dem TARMED interdisziplinär in kleinen Gruppen diskutieren.

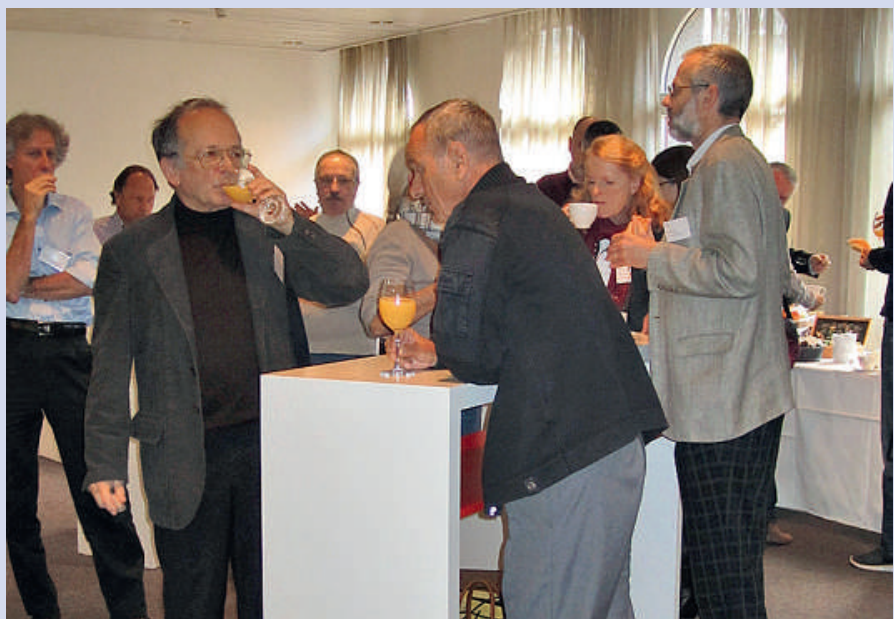

Natürlich wurden auch die Pausen und der Stehlunch am Mittag rege genutzt, um Kontakte unter den Tarifdelegierten der verschiedenen Fachgesellschaften neu zu knüpfen oder zu vertiefen.

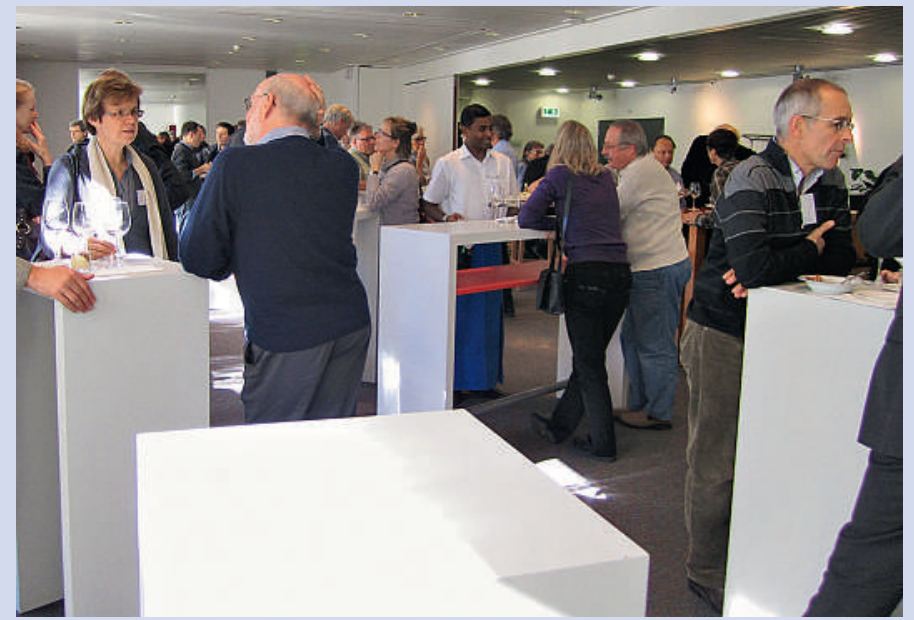

Insgesamt gesehen, herrschte am vergangenen Tarifdelegierten-Tag eine gute, konstruktive und optimistische Stimmung. Wir freuen uns daher schon auf das zahlreiche Erscheinen am nächsten Tarifdelegierten-Tag, am Donnerstag, 15. März 2012, wieder im Hotel Bern.

Alle Referate und Publikationen finden Sie auf der Homepage unter: FMH, Tarife, TARMED Tarif, Publikationen, Tarifdelegierten-Tag. 